\title{
Assessment of Patients Knowledge about Gastritis at General Kirkuk Hospital in Kirkuk City

\author{
Qasim Hussein Mohammed *
}

\begin{abstract}
Background and aim: Gastritis (inflammation of the gastric or stomach mucosa) is a common GI problem. Gastritis may be acute, lasting several hours to a few days, or chronic, resulting from repeated exposure to irritating agents or recurring episodes of acute gastritis). The aim of the study to assessment of patient Knowledge regarding gastritis at General Kirkuk Hospital in Kirkuk city.

Materials and method: descriptive study was carried out on gastritis patients at General Kirkuk hospital in Kirkuk city from the beginning from $\left(10^{\text {th }}\right.$ of June 2013 to $5^{\text {th }}$ May 2014) in order to assess knowledge concerning gastritis ,non- probability sampling convenience sample of (50) patients .The data was collected through the application of constructed questionnaire with consist of three parts and were used (SPSS). The Data were analyzed by using descriptive and inferential statistical the frequencies (F), percentage (\%), and mean of score.
\end{abstract}

Results : (74\%) of the samples (35>) years old, $(76 \%)$ of them were male, $(54 \%)$ of the samples were illiterate, $(62 \%)$ of them were house wife, $(88 \%)$ of the samples were married, $40 \%)$ of them were (4-6) Working hour per day , 32\%) of them have history of hypertension,(72\%) of the sample had no family history of gastritis, (66\%) of them no smoker, (78\%) of them had continuous stress.

Conclusion: type of the patients gender the highest age that having gastritis is (female), almost highest rate of the sample revealed illiterate of the patient. Majority of the sample show housewife occupational of patient. Almost majority of the sample showed that most of patient was married, The highest rate of patient who having gastritis was complain from chronic disease. The majority of samples were having continuous stress, The highest rate of patient was having good knowledge about medical treatment instruct the people about avoiding taking any medication without physician order.

Recommendation: Advice the people to take healthy diet and avoid irritant food, and decrease stress.

Keywords: Assessment, Knowledge, Gastritis.

\section{INTRODUCTION}

Gastritis (inflammation of the gastric or stomach mucosa) is a common GI problem. Gastritis may be acute, lasting several hours to a few days, or chronic, resulting from repeated exposure to irritating agents or recurring episodes of acute gastritis (Abir and Bell, 2004).

Acute gastritis is often caused by dietary indiscretion - the person eats food that is irritating, too highly seasoned, or contaminated with disease-causing microorganisms. Other causes of acute gastritis include overuse of aspirin and other no steroidal anti-inflammatory drugs (NSAIDs), excessive alcohol intake, bile reflux, and radiation therapy. A more severe form of acute gastritis is caused by the ingestion of strong acid or alkali, which may cause the mucosa to become gangrenous or to perforate. Scarring can occur, resulting in pyloric stenosis or obstruction. Acute gastritis also may develop in acute illnesses, especially when the patient has had major traumatic injuries; burns; severe infection; hepatic, renal, or respiratory failure; or major surgery. Gastritis may be the first sign of an acute systemic infection (Friedman, 2003).

Chronic gastritis and prolonged inflammation of the stomach may be caused either by benign or malignant ulcers of the stomach or by the bacteria Helicobacter pylori (H. pylori). Chronic gastritis is sometimes associated with autoimmune diseases such as pernicious anemia; dietary factors such as caffeine; the use of medications such as NSAIDs, bisphosphonate (ex, alendronate [Foamex], or risedronate [Actonel]); alcohol; smoking; or chronic reflux of pancreatic secretions and bile into the stomach (DeVita et. al., 2004).

The Importance of the study in the United States about 4 million people have active peptic ulcers and about 350,000 new cases are diagnosed each year. Four times as many duodenal ulcers as gastric ulcers are diagnosed. Approximately 3,000 deaths per year in the United States are due to duodenal ulcer and

* Assistant lecturer, M.Sc. in fundamental of Nursing / College of Nursing / Kirkuk University 
3,000 to gastric ulcer (Delgados-Aros et. al., 2004).

\section{MATERIALS AND METHOD}

The design of the present study was a descriptive study. The study was conducted at General Kirkuk Hospital from $1^{\text {st }}$ of July, 2013, up to the $1^{\text {th }}$ of April, 2014 to assessment of patients Knowledge regarding Gastritis. A non probability sampling (convenience) 50 of samples selected from the patients who were attended Azadi teaching hospital according to following criteria

1- Patients who has gastritis

2- Male and female

3- Patient age 20 above.

The researcher collected data through extensive review of relevant literature; a questionnaire was constructed for the purpose of the study with interview technique. Overall items included in the questionnaire were (51) items. All

\section{RESULTS}

Table (1): Distribution of the samples regarding demographic data of (50) patients with frequency and percentage

\begin{tabular}{|c|c|c|c|}
\hline No & Age(years) & Frequency & Percentage $(\%)$ \\
\hline 1 & $20<$ & 1 & 1 \\
\hline 2 & $21-25$ & 7 & 14 \\
\hline 3 & $26-30$ & 6 & 12 \\
\hline 4 & $35>$ & 37 & 74 \\
\hline \multicolumn{2}{|r|}{ Total } & 50 & 100 \\
\hline NO. & Gender & Frequency & $\%$ \\
\hline 1 & Male & 12 & 76 \\
\hline 2 & Female & 38 & 24 \\
\hline \multicolumn{2}{|r|}{ Total } & 50 & 100 \\
\hline NO. & Level of education & Frequency & $\%$ \\
\hline 1 & Illiterate & 27 & 54 \\
\hline 2 & Read \& write & 6 & 12 \\
\hline 3 & Primary school & 6 & 12 \\
\hline 4 & Intermediate school graduate & 3 & 6 \\
\hline 5 & Secondary school & 3 & 6 \\
\hline 6 & Institute graduate & 1 & 2 \\
\hline 7 & College graduate & 4 & 8 \\
\hline \multicolumn{2}{|r|}{ Total } & 50 & 100 \\
\hline NO. & Occupation & Frequency & $\%$ \\
\hline 1 & Governmental employed & 3 & 6 \\
\hline 2 & Free work & 5 & 10 \\
\hline 3 & Retired & 0 & 0 \\
\hline 4 & Hose wife & 31 & 62 \\
\hline 5 & Student & 1 & 4 \\
\hline 6 & Jobless & 9 & 18 \\
\hline \multicolumn{2}{|r|}{ Total } & 50 & 100 \\
\hline NO. & Marital status & Frequency & $\%$ \\
\hline 1 & Single & 6 & 12 \\
\hline
\end{tabular}




\begin{tabular}{||c|c|c|c|}
\hline 2 & Married & 44 & 88 \\
\hline \multicolumn{2}{|c|}{ Total } & 50 & 100 \\
\hline NO. & Monthly income & Frequency & $\%$ \\
\hline 1 & Sufficient & 20 & 40 \\
\hline 2 & Barely sufficient & 22 & 44 \\
\hline 3 & Insufficient & 8 & 16 \\
\hline \multicolumn{2}{|c|}{ Total } & Frequency & 100 \\
\hline NO. & Working hour per day & 14 & 28 \\
\hline 1 & Has no working hours & 4 & 8 \\
\hline 2 & $1-3$ & 20 & 40 \\
\hline 3 & $4-6$ & 12 & 24 \\
\hline 4 & $>7$ hours & 50 & 100 \\
\hline
\end{tabular}

The table (1) shows that (74\%) of the samples (35>) years old, (76\%) of them were male, (54\%) of the samples were illiterate, $(62 \%)$ of them were house wife, $(88 \%)$ of the samples were married, $(44 \%)$ of them had barely sufficient income, (40\%) of them were (4-6) Working hour per day.

Table (2) Distribution of the samples regarding medical data of (50) patients with frequency and percentage

\begin{tabular}{|c|c|c|c|}
\hline No. & Duration of disease & Frequency & Percentage\% \\
\hline 1 & $\leq 1$ year & 21 & 42 \\
\hline 2 & $2-5$ years & 18 & 36 \\
\hline 3 & 5 years and more & 11 & 22 \\
\hline \multicolumn{2}{|r|}{ Total } & 50 & 100 \\
\hline No & Chronic disease & Frequency & $\%$ \\
\hline 1 & Heart disease & 15 & 26 \\
\hline 2 & Renal disease & 5 & 10 \\
\hline 3 & Hypertension & 26 & 32 \\
\hline 4 & Diabetes mellitus & 4 & 8 \\
\hline \multicolumn{2}{|r|}{ Total } & 50 & 100 \\
\hline No & Medication & Frequency & $\%$ \\
\hline 1 & Omeprazole & 36 & 72 \\
\hline 2 & Zantac & 13 & 26 \\
\hline 3 & Metronidazole & 1 & 2 \\
\hline \multicolumn{2}{|r|}{ Total } & 50 & 100 \\
\hline No & Family history & Frequency & $\%$ \\
\hline 1 & Yes & 14 & 28 \\
\hline 2 & No & 36 & 72 \\
\hline \multicolumn{2}{|r|}{ Total } & 50 & 100 \\
\hline No & Smoking & Frequency & $\%$ \\
\hline 1 & Yes & 9 & 18 \\
\hline 2 & No & 33 & 66 \\
\hline 3 & Ex_smoker & 8 & 16 \\
\hline \multicolumn{2}{|r|}{ Total } & 50 & 100 \\
\hline No & Do you have continues stress & Frequency & $\%$ \\
\hline 1 & Yes & 39 & 78 \\
\hline 2 & No & 11 & 22 \\
\hline \multicolumn{2}{|r|}{ Total } & 50 & 100 \\
\hline
\end{tabular}

This table shows that $(42 \%)$ of the samples have $\leq 1$ year, $(32 \%)$ of them have history of hypertension, $(26 \%)$ of the samples taking Omeprazole, $(72 \%)$ of the sample had no family history of gastritis, $(66 \%)$ of them no smoker, $(78 \%)$ of them had continuous stress 
Table (3) Patient's knowledge regarding cause of gastritis.

\begin{tabular}{|c|c|c|c|c|c|c|c|}
\hline \multirow{2}{*}{ No } & \multirow{2}{*}{ Cause of gastritis } & \multicolumn{2}{|c|}{ Yes } & \multicolumn{2}{|c|}{ No } & \multirow{2}{*}{ MS } & \multirow{2}{*}{ Sig. } \\
\hline & & $\mathrm{F}$ & $\%$ & $\mathrm{~F}$ & $\%$ & & \\
\hline 1 & Aspirin & 14 & 28 & 36 & 72 & 1.2 & $\mathrm{~L}$ \\
\hline 2 & Alcohol & 42 & 84 & 8 & 16 & 1.8 & $\mathrm{H}$ \\
\hline 3 & Helicobacter pylori infection & 38 & 76 & 12 & 24 & 1.7 & $\mathrm{H}$ \\
\hline 4 & Smoking & 47 & 94 & 3 & 6 & 1.9 & $\mathrm{H}$ \\
\hline 5 & Stress & 42 & 84 & 8 & 16 & 1.8 & $\mathrm{H}$ \\
\hline 6 & Burn & 21 & 42 & 29 & 58 & 1.4 & $\mathrm{M}$ \\
\hline 7 & Spicy irritant food & 44 & 88 & 6 & 12 & 1.8 & $\mathrm{H}$ \\
\hline 8 & Trauma & 23 & 46 & 27 & 54 & 1.4 & $\mathrm{M}$ \\
\hline 9 & Endoscopic technique & 12 & 24 & 38 & 76 & 1.2 & $\mathrm{M}$ \\
\hline
\end{tabular}

The table (3) shows that the samples has good knowledge in items $(2,3,4,5,7)$ and had poor in items $(1,6,8.9)$

Table (4) Patient's knowledge regarding Sign and symptoms of gastritis.

\begin{tabular}{|c|c|c|c|c|c|c|c|}
\hline \multirow{2}{*}{ No } & \multirow{2}{*}{ Sign and symptoms } & \multicolumn{2}{|c|}{ Yes } & \multicolumn{2}{|c|}{ No } & \multirow{2}{*}{ MS } & \multirow{2}{*}{ sig. } \\
\cline { 3 - 8 } & F & $\%$ & F & $\%$ & & \\
\hline 1 & Nausea and vomiting & 39 & 78 & 11 & 22 & 1.7 & H \\
\hline 2 & Anorexia & 38 & 76 & 12 & 24 & 1.7 & H \\
\hline 3 & Weight loss & 34 & 68 & 16 & 32 & 1.6 & H \\
\hline 4 & Epigastric pain & 48 & 96 & 2 & 4 & 1.9 & H \\
\hline 5 & Abdominal bleeding & 9 & 18 & 41 & 82 & 1.1 & L \\
\hline 6 & Hiccups & 34 & 68 & 16 & 32 & 1.6 & H \\
\hline 7 & Fee king of fullness & 25 & 50 & 25 & 50 & 1.5 & M \\
\hline 8 & Blood in vomitus & 7 & 14 & 43 & 86 & 1.1 & L \\
\hline 9 & Blood in stool & 8 & 16 & 42 & 84 & 1.1 & L \\
\hline
\end{tabular}

The table (4) shows that the samples has good knowledge in all items except items $(1,2,3,4,6)$

Table (5) Patient's knowledge regarding Diagnostic tests of gastritis

\begin{tabular}{|c|c|c|c|c|c|c|c|}
\hline \multirow{2}{*}{ No } & \multirow{2}{*}{ Diagnostic tests } & \multicolumn{2}{|c|}{ Yes } & \multicolumn{2}{|c|}{ No } & \multirow{2}{*}{ MS } & \multirow[b]{2}{*}{ sig. } \\
\hline & & $\mathrm{F}$ & $\%$ & $\mathrm{~F}$ & $\%$ & & \\
\hline 1 & Complete blood count & 24 & 48 & 26 & 52 & 1.4 & $\mathrm{~L}$ \\
\hline 2 & Stool sample & 14 & 28 & 36 & 72 & 1.2 & $\mathrm{~L}$ \\
\hline 3 & $\mathrm{X}-$ ray & 32 & 64 & 18 & 36 & 1.6 & $\mathrm{H}$ \\
\hline 4 & Gastroscopy & 8 & 16 & 42 & 84 & 1.1 & $\mathrm{~L}$ \\
\hline 5 & Stomach biopsy & 15 & 30 & 35 & 70 & 1.3 & $\mathrm{~L}$ \\
\hline
\end{tabular}

The table (5) shows that the samples had poor knowledge in all items except items (3) had good knowledge.

Table (6) Patients knowledge regarding Medical treatment of gastritis

\begin{tabular}{|c|l|c|c|c|c|c|c||}
\hline \multirow{2}{*}{ No } & \multirow{2}{*}{ Medical treatment } & \multicolumn{2}{c|}{ Yes } & \multicolumn{2}{c|}{ No } & \multirow{2}{*}{ MS } & \multirow{2}{*}{ sig. } \\
\cline { 3 - 8 } & & $\mathrm{F}$ & $\%$ & $\mathrm{~F}$ & $\%$ & & $\mathrm{H}$ \\
\hline 1 & Bed rest & 43 & 86 & 7 & 14 & 1.8 & $\mathrm{M}$ \\
\hline 2 & Reduce anxiety & 27 & 54 & 23 & 46 & 1.5 & $\mathrm{H}$ \\
\hline 3 & Intra Venus fluids electrolytes & 35 & 70 & 15 & 30 & 1.7 & $\mathrm{H}$ \\
\hline 4 & Avoid caffeine & 32 & 64 & 18 & 36 & 1.6 & $\mathrm{H}$ \\
\hline 5 & Avoid alcohol & 45 & 90 & 5 & 10 & 1.9 & $\mathrm{M}$ \\
\hline 6 & Avoid aspirin & 16 & 32 & 34 & 68 & 1.3 & $\mathrm{H}$ \\
\hline 7 & Prevent smoking & 48 & 96 & 2 & 4 & 1.9 & $\mathrm{M}$ \\
\hline 8 & Anti-emetic drug & 20 & 40 & 30 & 60 & 1.4 & $\mathrm{~L}$ \\
\hline 9 & Antacid & 5 & 10 & 45 & 90 & 1.1 & $\mathrm{~L}$ \\
\hline 10 & Stomach acid blocker (Omeprazole) & 13 & 26 & 37 & 74 & 1.2 & $\mathrm{H}$ \\
\hline 11 & Small and frequent meal & 46 & 92 & 4 & 8 & 1.9 & $\mathrm{H}$ \\
\hline
\end{tabular}

The table (6) shows that the samples have good knowledge in all items except items $(1,3,4,5,7$, and 11) 
Table (7) Patient's knowledge regarding Complication of gastritis of gastritis

\begin{tabular}{|c|l|c|c|c|c|c|c|c|}
\hline \multirow{2}{*}{ No } & \multirow{2}{*}{ Complication of gastritis } & \multicolumn{2}{|c|}{ Yes } & \multicolumn{2}{|c|}{ No } & \multirow{2}{*}{ MS } & \multirow{2}{*}{ sig. } \\
\cline { 3 - 7 } & & $\mathrm{F}$ & $\%$ & $\mathrm{~F}$ & $\%$ & & $\mathrm{H}$ \\
\hline 1 & Gastritis ulcer & 31 & 62 & 19 & 38 & 1.6 & $\mathrm{M}$ \\
\hline 2 & Gastric bleeding & 14 & 28 & 36 & 72 & 1.2 & $\mathrm{~L}$ \\
\hline 3 & Stomach cancer & 6 & 12 & 44 & 88 & 1.1 & $\mathrm{~L}$ \\
\hline
\end{tabular}

The table (7) shows that the samples have poor knowledge in all items except items (1)

\section{DISCUSSION}

Regarding the demographic data in table (1), shows that $(74 \%)$ of the samples (35>) years old, $(76 \%)$ of them were male, $(54 \%)$ of the samples were illiterate, $(62 \%)$ of them were house wife, $(88 \%)$ of the samples were married, $(44 \%)$ of them had barely sufficient income, (40\%) of them were (4-6) Working hour per day. The study agree with (Mayo clinic, 2014) who stated in a study that the prevalence rate of gastritis increase significantly with age, while the same disagree with our study regarding gender distribution of gastritis that who mentioned that there is no difference between the sexes for distribution of gastritis (Mayo clinic Gastritis complication of gastritis, 2014).

Regarding medical data Table (2) shows that $(42 \%)$ of the samples have $\leq 1$ year, $(32 \%)$ of them have history of hypertension, $(26 \%)$ of the samples taking Omeprazole, $(72 \%)$ of the sample had no family history of gastritis, $(66 \%)$ of them no smoker, (78\%) of them had continuous stress.

The result findings agree with Gunnar $\mathrm{H}$, (2004) who mentioned that gastritis is a common GI problem. Gastritis may be acute, lasting several hours to a few days, or chronic, resulting from repeated exposure to irritating agents or recurring episodes of acute gastritis. Patients knowledge regarding cause of gastritis in table (3) shows that the samples has good knowledge in items $(2,3,4,5,7)$ and had poor in items $(1$, 6, 8.9) (Ferraro, 2004).

The finding result supported by Ferraro, (2004) who stated that acute gastritis is often caused by dietary indiscretion - the person eats food that is irritating, too highly seasoned, or contaminated with disease-causing microorganisms. Other causes of acute gastritis include overuse of aspirin and other no steroidal antiinflammatory drugs (NSAIDs), excessive alcohol intake, bile reflux, and radiation therapy. A more severe form of acute gastritis is caused by the ingestion of strong acid or alkali, which may cause the mucosa to become gangrenous or to perforate. Scarring can occur, resulting in pyloric stenosis or obstruction. Acute gastritis also may develop in acute illnesses, especially when the patient has had major traumatic injuries; burns; severe infection; hepatic, renal, or respiratory failure; or major surgery. Gastritis may be the first sign of an acute systemic infection (Padwal et. al., 2004)

The study agrees with Padwal and Lau, (2004) who stated that chronic gastritis and prolonged inflammation of the stomach may be caused either by benign or malignant ulcers of the stomach or by the bacteria Helicobacter pylori (H. pylori). Chronic gastritis is sometimes associated with autoimmune diseases such as pernicious anemia; dietary factors such as caffeine; the use of medications such as NSAIDs, bisphosphonate (e.g., alendronate [Fosamax], or risedronate [Actonel]); alcohol; smoking; or chronic reflux of pancreatic secretions and bile into the stomach. Patient's knowledge regarding Sign and symptoms of gastritis in Table (4) shows that the samples has good knowledge in all items except items $(5,8$, 9) (Brown et. al., 2002).

The study agree with Brown et al., (2002) who mentioned that acute gastritis may have a rapid onset of symptoms, such as abdominal discomfort, headache, lassitude, nausea and vomiting, anorexia, hiccupping which can last from a few hours to a few days. The patient with chronic gastritis may complain of anorexia, heartburn after eating, belching, a sour taste in the mouth, nausea and vomiting, some patients may have only mild epigastric discomfort or report intolerance to spicy or fatty foods or slight pain that is relieved by eating (National Digestive Disease, 2013).

Regarding Patients' knowledge of Diagnostic tests of gastritis, Table (4) shows that the sample has poor knowledge in all items except items (3) had good knowledge. The study agree with NDDIC, ( 2014) who stated that the most common diagnostic test for gastritis is endoscopy with a biopsy of the stomach, gastrointestinal (GI) series, Blood test., Stool test. Tests for $\mathrm{H}$. pylori infection Regarding Patient's knowledge of Medical treatment of gastritis with frequency,) shows that the samples have good knowledge in all items except items $(6,8,9,1)$ (Zajac et. al., 2013). The study agree with Zajac et al. (2013) who mentioned that Over-the-counter antacids in liquid or tablet 
form are a common treatment for mild gastritis. When antacids do not provide enough relief, medications such as cimetidine, ranitidine, nizatidine or famotidine that help reduce the amount of acid the stomach produces are often prescribed. An even more effective way to limit stomach acid production is to shut down the acid "pumps" within acid-secreting stomach cells (Wang and Peura, 2011).

Patient's knowledge regarding Complication of gastritis shows that the samples have poor knowledge in all items except items (1). The study agree with Roger et al., (2002) who mentioned that left untreated, gastritis may lead to stomach ulcers and stomach bleeding. Some forms of chronic gastritis may increase risk of stomach cancer, especially if have extensive thinning of the stomach lining and changes in the lining's cells (Kandulski et. al., 2008).

\section{CONCLUSION}

The study concluded that most of age of the patients (35>) years old, type of the patients gender the highest age that having gastritis is (female), Almost highest rate of the sample revealed illiterate of the patient. Majority of the sample show housewife occupational of patient. Almost majority of the sample showed that most of patient was married. The highest rate duration of disease of the patient that having gastritis was ( $\leq 1$ year). The highest rate of patient who having gastritis was complained from chronic disease (hypertension), a patient who was having gastritis was taking omperazol) tablet and more rate of the sample shows that their families weren't having heredity gastritis the more rate of patient who having gastritis was no smoking. The majority of samples were having continuous stress. The majority rate of patient having good knowledge that smoking is the most common causes of gastritis the highest rate of patient was having good knowledge about the sign and symptom's of gastritis (blood in vomiting, blood in stool, abdominal bleeding). The more rate of patient was having good knowledge about the diagnostic tests (x-ray). The highest rate of patient was having good knowledge about medical treatment except (avoid aspirin, antiemetic drug, anti acid, stomach acid blocker). Finally, more rate of patient was having good knowledge about gastritis complication (gastric ulcer).

\section{RECOMMENDATIONS}

The study concludes that instruct the people about avoiding taking any medication without a physician order. Advise the people to follow healthy lifestyle, such as exercise, etc. Every person should do diagnostic tests periodically to detect if they was any medical problem especially the initial diagnosis of gastritis. Finally, Advice the people to take healthy diet and avoid irritant food. Instruct the people to avoid alcohol intake and smoking

\section{REFERENCES}

Abir, F., and Bell, R. (2004). Assessment and management of the obese patient. Critical Care Medicine. 32(Supple)(4). P.p. 87-91.

Delgados-Aros, S.; Locke, R.; Camilleri, M.; et al. (2004). Obesity is associated with increased risk of gastrointestinal symptoms: A population-based study. American Journal of Gastroenterology. 99(9).1801.

DeVita, V. T.; Hellman, S.; and Rosenberg, S. A. (2004). Cancer: Principles and practice of oncology. ( $7^{\text {th }} \quad$ Ed.). Philadelphia: Lippincott Williams \& Wilkins.

Ferraro, D. R. (2004). Preparing patients for bariatric surgery: The clinical considerations. Clinician Reviews. 14(1). P.p, 58-63

Friedman, S. L.; McQ. (2003). uaid, K. R., and Grendell, J. H. (Eds.). Current diagnosis and treatment in gastroenterologyNew. York: McGraw-Hill.

Kandulski A.; Selgrad M.; and Malfertheiner P. (2008). "Helicobacter pylori infection: a clinical overview". Digestive and Liver Disease 40 (8): 619-26.

Mayo clinic Gastritis complication of gastritis, (2014).

National Digestive Disease. (2013). information cleaning house the Digestive system and it works,

Padwal, R., Li., S. K.; and Lau, D. C. (2004). Long-term pharmacology for obesity and overweight. Cochrane Database of Systematic Reviews. (135). 32-37.

Wang, AY; and Peura, DA. (2011). "The prevalence and incidence of Helicobacter pylori-associated peptic ulcer disease and upper gastrointestinal bleeding throughout the world.". Gastrointestinal endoscopy clinics of North America. 21(4): 613-35.

Zajac, P.; Holbrook, A.; Super, ME.; Vogt, M. (2013). "An overview: Current clinical guidelines for the evaluation, diagnosis, treatment, and management of dyspepsia". Osteopathic Family Physician. 5(2):79-85. 